\title{
Observing river stages using unmanned aerial vehicles
}

\author{
Tomasz Niedzielski, Matylda Witek, and Waldemar Spallek \\ Department of Geoinformatics and Cartography, Faculty of Earth Science and Environmental Management, \\ University of Wrocław, pl. Uniwersytecki 1, 50-137 Wrocław, Poland
}

Correspondence to: Tomasz Niedzielski (tomasz.niedzielski@uwr.edu.pl)

Received: 27 January 2016 - Published in Hydrol. Earth Syst. Sci. Discuss.: 1 February 2016

Revised: 29 June 2016 - Accepted: 4 July 2016 - Published: 9 August 2016

\begin{abstract}
We elaborated a new method for observing water surface areas and river stages using unmanned aerial vehicles (UAVs). It is based on processing multitemporal five orthophotomaps produced from the UAV-taken visible light images of nine sites of the river, acquired with a sufficient overlap in each part. Water surface areas are calculated in the first place, and subsequently expressed as fractions of total areas of water-covered terrain at a given site of the river recorded on five dates. The logarithms of the fractions are later calculated, producing five samples, each consisted of nine elements. In order to detect statistically significant increments of water surface areas between two orthophotomaps, we apply the asymptotic and bootstrapped versions of the Student's $t$ test, preceded by other tests that aim to check model assumptions. The procedure is applied to five orthophotomaps covering nine sites of the Ścinawka river (south-western (SW) Poland). The data have been acquired during the experimental campaign, at which flight settings were kept unchanged over nearly 3 years (2012-2014). We have found that it is possible to detect transitions between water surface areas associated with all characteristic water levels (low, mean, intermediate and high stages). In addition, we infer that the identified transitions hold for characteristic river stages as well. In the experiment we detected all increments of water level: (1) from low stages to mean, intermediate and high stages; (2) from mean stages to intermediate and high stages; and (3) from intermediate stages to high stages. Potential applications of the elaborated method include verification of hydrodynamic models and the associated predictions of high flows as well as monitoring water levels of rivers in ungauged basins.
\end{abstract}

\section{Introduction}

A key problem in assessing performance of distributed hydrodynamic models, which predict water depth across a river channel and can therefore be used to simulate flood extent, is access to up-to-date information on true inundation. There are numerous approaches used to carry out such observations of inundation. They include terrestrial observations of flood damage carried out by volunteers, who witnessed the flood, following the concept of volunteered geographic information (VGI) (e.g. Poser and Dransch, 2010), geomorphological survey and a subsequent mapping of landforms produced as a consequence of a high flow (e.g. Latocha and Parzóch, 2010), aerial photogrammetry (e.g. Yu and Lane, 2006a), use of satellite remote sensing (e.g. Smith, 1997; Kouraev et al., 2004), application of airborne light detection and ranging (lidar) measurements (Lang and McCarty, 2009) as well as use of photographs taken by unmanned aerial vehicles (UAVs) (Witek et al., 2014). However, only a few on demand solutions exist that allow for real-time acquisition of such data (e.g. Schnebele et al., 2014). One of these solutions is the integration of HydroProg, FloodMap and UAV, known hereinafter as HFU, which has been proposed by Niedzielski et al. (2015) after the initial feasibility study offered by Witek et al. (2014).

The HFU approach utilizes the UAV observations carried out in near real time, i.e. when the integrated HydroProg (Niedzielski et al., 2014; Niedzielski and Miziński, 2016) and FloodMap (Yu and Lane, 2006a, b) solutions produce a real-time warning of predicted inundation. According to Niedzielski et al. (2015), the workflow of the HFU is the following: (1) HydroProg computes a hydrograph prediction based on a multimodel ensemble for $3 \mathrm{~h}$ into the future (this is done routinely in real time with a predefined frequency), 
(2) FloodMap uses the above-mentioned forecast as an input and enables mapping the hydrograph prognosis into the spatial domain (this is also done routinely in real time with the same frequency), (3) the warning is issued and the UAV team is notified (to be done only when a number of inundated raster cells exceeds a certain threshold), (4) the UAV team carries out the survey in order to take aerial photographs of the river channel (not routinely, but only after a warning has been issued). It is known that hydrodynamic models may produce incorrect simulations, and this is also likely in the case of the HydroProg-FloodMap integration. The outputs from this integration are maps of predicted extent of terrain covered by water, known also as water surface area. Thus, in order to verify such outputs we propose to compare the aforementioned maps with the orthophotomaps produced from the UAV-acquired visible light photographs taken in near real time.

Although such a stepwise procedure is conceptually complete, there is no clear picture of whether it is possible to detect changes in water extent using the UAV-based orthophotomaps. This paper aims to check the meaningfulness of the UAV-based observations of water surface areas. In order to prove the aforementioned HFU concept we herein aim to verify the research hypothesis, which reads as follows: "small changes in water surface areas are observable using the UAV". Such small changes may occur, for instance, when river stages rise from mean to high levels, which does not always produce inundation (i.e. when water does not pass embankments or river banks, but only sinks into old river channels, flows through flood shortcuts or fills the current river channel). In order to explain such changes we graphically present the difference between water extents during low and high stages (Fig. 1). Since water surface area is directly associated with river stage (Usachev, 1983; Smith, 1997), our problem of detecting the above-mentioned changes is equivalent to seeking significant transitions in river stages. In other words, our hypothesis can also read as follows: "meaningful changes in river stages are observable using the UAV".

Both flood extents and water levels of large rivers are observable from satellites. For observing water surface areas, the following satellite-acquired measurements are used: high-resolution visible light images or infrared images, passive microwave data and radar images. For observing water levels from satellites, researchers utilize radar altimetry and high-resolution satellite imagery. Since 1997, when the extensive review of the above-mentioned methods was published (Smith, 1997), numerous studies on observing water surface areas and water levels using remote sensing techniques have been carried out (Cobby et al., 2001; Kouraev et al., 2004; Prigent et al., 2007; Schnebele et al., 2014). However, these approaches are targeted at large rivers, and there are few methods to observe water surface areas, and hence water levels of small rivers. This paper aims to propose such an approach and to confirm its potential experimentally.
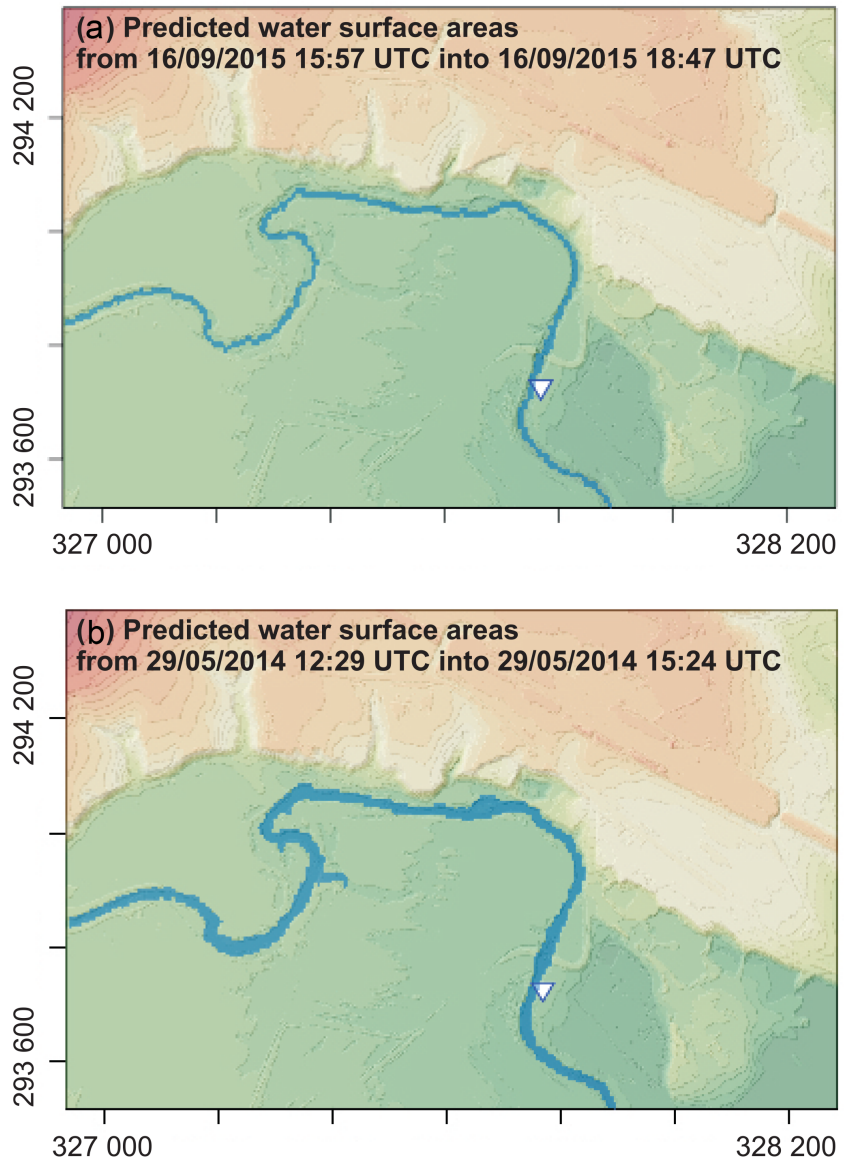

$\nabla$ Hydrologic gauges $\quad$ - Water surface areas

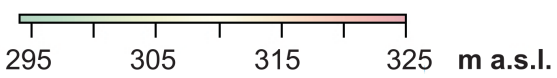

Figure 1. Predictions of water surface areas derived by the HydroProg-FloodMap solution (Niedzielski et al., 2015) extracted from the real-time web map service experimentally implemented for Kłodzko County: (a) low-flow situation, (b) high-flow situation.

In order to verify the above-mentioned hypothesis we use a time series of five orthophotomaps produced from aerial photographs taken by a UAV at different hydrologic situations that occurred along the Ścinawka river (south-western (SW) Poland). The observations were made in the experiment during which aerial images were acquired with a UAV flying on different dates, at the same altitude and over the same terrain. We adopt a rigorous statistical analysis, based on the asymptotic and bootstrapped Student's $t$ test, the use of which is essential in the process of detecting changes in water surface area. The remainder of this paper is organized as follows: the second section presents the study area and data, the subsequent section focuses on the UAV-based photo acquisition techniques and statistical methods, the fourth section shows 


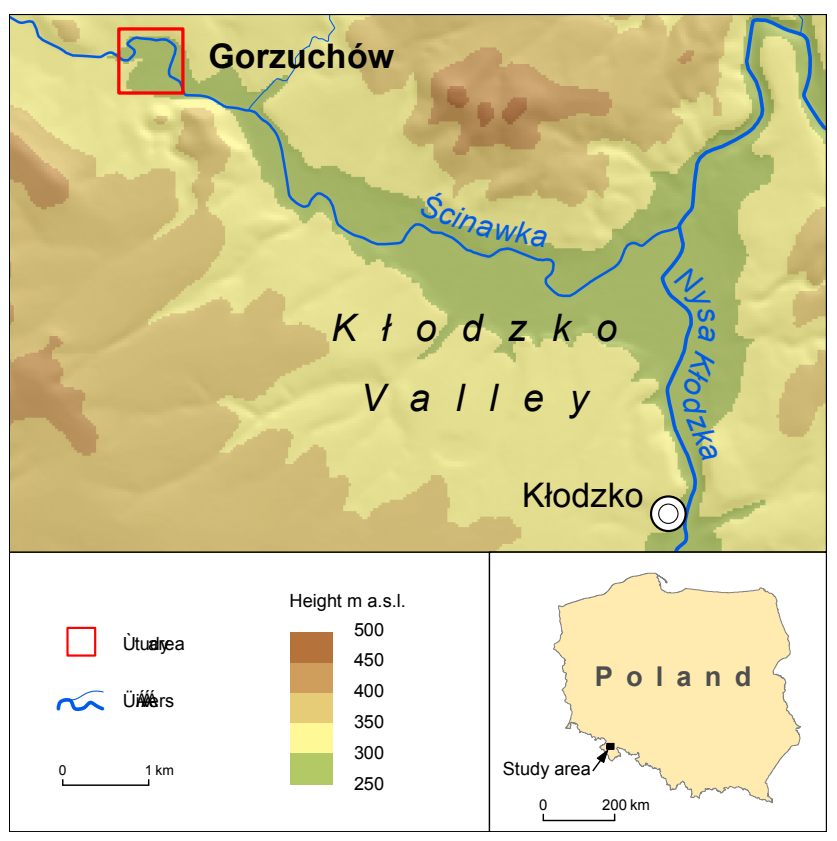

Figure 2. Map of study area.

the results and their discussion, while the last section concludes the paper.

\section{Data}

\subsection{Study area}

The research was conducted in south-western Poland, in Kłodzko County located in central and eastern Sudetes (Fig. 2). The main river of the region is Nysa Kłodzka (left tributary of the Odra river), and one of its key tributaries is the Ścinawka river.

The majority of rivers in Kłodzko County in their upper sections are typical mountain streams. The middle and lower sections of the channels, located in the foothills of the mountains, have alluvial character - wide channels with numerous large cutbanks, bars and meandering parts. The complex topography and the extensive hydrographic network contribute to rapid and catastrophic floods in this area (Dubicki et al., 2005; Kasprzak, 2010).

One of the alluvial-type river sections is a fragment of the Ścinawka river channel located directly upstream the Gorzuchów gauge $\left(50^{\circ} 29^{\prime} \mathrm{N}, 16^{\circ} 34^{\prime} \mathrm{E} ; 8.030 \mathrm{~km}\right.$ from mouth of river). The analysed part of the channel has a length of $1500 \mathrm{~m}$ and belongs to the lower part of the basin, within which the Ścinawka river flows through a wide valley (250$400 \mathrm{~m}$ ) with a flat bottom. The river banks in the studied part are asymmetrical. The width of the channel, in the investigated part, varies between 5 and $25 \mathrm{~m}$, and the average slope of the channel is $3.4 \%$. This part of the river has a winding character, and is contemporary formed mainly by lat-

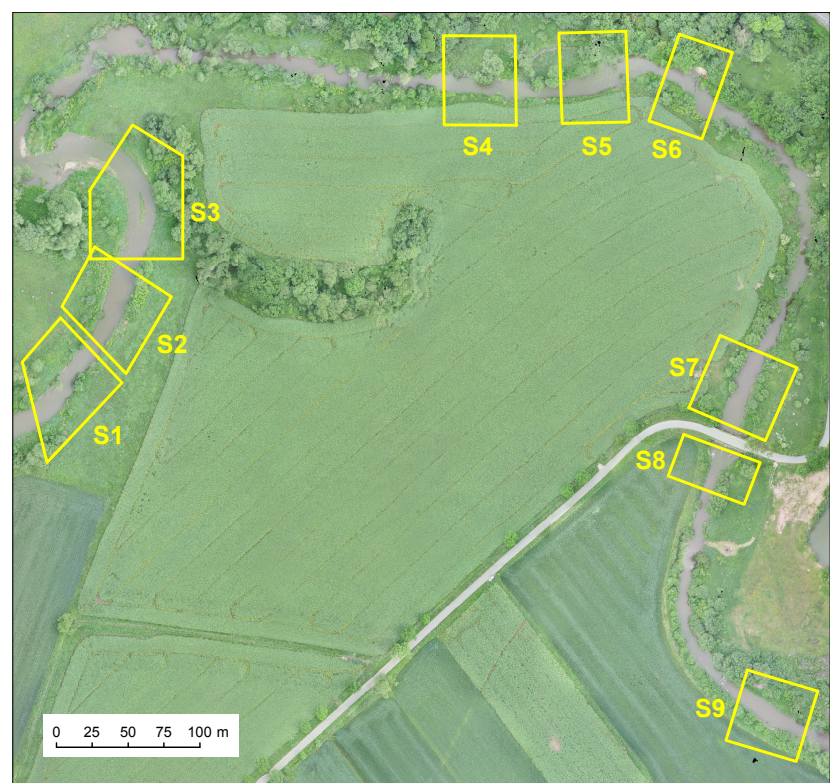

Figure 3. Study sites on the Ścinawka river in Gorzuchów. Numbers in site codes increase in a downstream direction.

eral erosion. The analysed section is located far from human settlements; hence, regulation works have not been undertaken here. Soft material forming the river bed and banks as well as lack of engineering structures and occurrence of frequent flood episodes provide profound conditions for development of erosion and accumulation channel landforms. Evident channel bedforms are visible, for instance steep banks of erosional origin reveal heights of $1.5-2 \mathrm{~m}$. As regards accumulation-driven forms, various types of bars are common in the studied channel, with point bars and longitudinal ones that reflect the characteristics of a meandering stream.

The channel morphology of the studied part of the Ścinawka river may be linked to the pool-riffle channel pattern, with exposed bars and highly turbulent flow through riffles and more tranquil flow through pools. The average annual discharge at the Gorzuchów gauge is approximately equal to $4.63 \mathrm{~m}^{3} \mathrm{~s}^{-1}$ (1951-2011), whereas the average annual water level is of $71.6 \mathrm{~cm}(1981-2011)$.

In the studied fragment of the Ścinawka channel nine sites of variable lengths have been selected and coded as S1, S2, ..., S9 (Fig. 3). Water extents in different seasons are analysed in these sites. The UAV observations have been carried out on 27 November 2012, 13 May 2013, 21 August 2013, 27 September 2013 and 2 June 2014. Table 1 presents detailed parameters of the UAV flight trajectories, with a particular emphasis put on the UAV vertical position. It is apparent from the table that those parameters were kept similar and stable over the above-mentioned five flight missions. Hence, the resulting data sets are of comparable resolution, and the level of details of aerial images and the resulting orthophotomaps is similar. 
Table 1. Vertical flight parameters during the UAV missions on 27 November 2012, 13 May 2013, 21 August 2013 , 27 September 2013 and 2 June 2014.

\begin{tabular}{|c|c|c|c|c|c|c|c|c|}
\hline $\begin{array}{l}\text { Date and number } \\
\text { of flight }\end{array}$ & $\begin{array}{l}\text { Planned height above } \\
\text { takeoff location } \\
\text { (m) }\end{array}$ & $\begin{array}{l}\text { Takeoff } \\
\text { altitude } \\
\text { (m a.s.1.) }\end{array}$ & $\begin{array}{l}\text { Maximum } \\
\text { height } \\
\text { (m) }\end{array}$ & $\begin{array}{l}\text { Mean } \\
\text { height } \\
(\mathrm{m})\end{array}$ & $\begin{array}{l}\text { Maximum } \\
\text { altitude } \\
\text { (m a.s.l.) }\end{array}$ & $\begin{array}{c}\text { Mean } \\
\text { altitude } \\
\text { (m a.s.l.) }\end{array}$ & $\begin{array}{l}\text { Maximum } \\
\text { altitude WGS84 } \\
\text { (m) }\end{array}$ & $\begin{array}{l}\text { Mean } \\
\text { altitude WGS84 } \\
\text { (m) }\end{array}$ \\
\hline $27 / 11 / 2012(1)$ & 109.0 & 296.4 & 113.6 & 109.2 & 410.0 & 405.6 & 451.0 & 447.5 \\
\hline $27 / 11 / 2012(2)$ & 109.0 & 296.5 & 112.4 & 109.1 & 408.9 & 405.7 & 453.5 & 447.9 \\
\hline $13 / 05 / 2013(1)$ & 109.0 & 297.7 & 116.0 & 108.9 & 413.7 & 406.6 & 456.2 & 449.9 \\
\hline $13 / 05 / 2013(2)$ & 109.0 & 299.8 & 118.1 & 109.0 & 417.9 & 408.8 & 458.6 & 450.4 \\
\hline $21 / 08 / 2013(1)$ & 109.0 & 301.1 & 117.0 & 108.2 & 418.2 & 409.3 & 458.8 & 450.6 \\
\hline $21 / 08 / 2013(2)$ & 109.0 & 295.2 & 115.0 & 108.9 & 410.2 & 404.1 & 450.0 & 444.8 \\
\hline 27/09/2013 (1) & 109.0 & 294.5 & 114.8 & 108.8 & 409.3 & 403.4 & 452.7 & 455.5 \\
\hline $27 / 09 / 2013(2)$ & 109.0 & 295.5 & 114.5 & 109.1 & 410.0 & 404.6 & 454.3 & 446.4 \\
\hline 2/06/2014 (1) & 109.0 & 305.3 & 115.3 & 108.3 & 420.7 & 413.6 & 452.7 & 461.0 \\
\hline $2 / 06 / 2014(2)$ & 109.0 & 294.3 & 114.3 & 108.9 & 408.6 & 403.1 & 451.1 & 445.4 \\
\hline
\end{tabular}

The selection of the sites is based on the following conditions: (1) all sites are covered by the observations from the above-mentioned five dates, (2) there are no distortions of the produced orthophotomaps (i.e. no-data masks or incorrect peripheries, both arising from the limited coverage of aerial photos), (3) the sites are characterized by different morphological positions, they cover channel landforms and enable one to observe water extent, (4) the sites cannot be covered by lush vegetation, which prevents the identification of riverbanks.

\subsection{UAV data processing}

We carried out the UAV survey using the swinglet CAM fixed-wing solution manufactured by senseFly. Swinglet CAM is lightweight $(0.5 \mathrm{~kg})$ and its payload includes a single consumer-grade RGB camera that records the photographs as JPG files. The individual pictures are geotagged. In order to produce orthophotomaps we process these files with the structure-from-motion (SfM) algorithm (Westoby et al., 2012) in the Photoscan software provided by AgiSoft, without use of ground control points (GCPs). We produced the georeferenced orthophotomaps in Photoscan, which for the purpose of georeferencing uses coordinates extracted from the geotagged images. Such orthophotomaps were compared with the lidar digital terrain model (DTM), and we identified offsets between the two. The resolution of the lidar data was of $1 \mathrm{~m}$, and the data acquisition was carried out in 2010 . To remove the offsets we used the spline function in ArcMap 10.2.2 by ESRI. We identified characteristic features in the lidar DTM, which were evenly distributed and possible to identify in the orthophotomap. These features comprise: crossings of bounds, crossings of drainage ditches, and centres of bridges or passages (crossings of streams and roads). More than 10 points were used to perform georeferencing, as the spline method requires. The spline function allowed us to precisely georeference the control points (i.e. the aforementioned mutual features) and transform raster data sets with continuity and smoothness, such as the rubber sheeting method. Use of lidar data to improve spatial references of UAV-acquired materials is known (Liu et al., 2007). However, these authors use lidar data to improve the quality of GCPs, and our approach is different as it applies splines to provide a spatial fix and correct for errors.

Although we did not use GCPs in the process of orthophotomap generation, we believe that for the purpose of the proposed analysis the absolute fit of orthophotomap to the Earth-fixed reference is not as crucial as the internal accuracy (within the orthophotomap). Indeed, the accuracy of area computation is not sensitive to linear motions of the cartographic source, but is vulnerable to the quality of the sources, and the latter is guaranteed by the above-mentioned lidarbased procedure that can be repeated at any time. Temporal analysis of landform topography is associated with a need of high accuracy, which is guaranteed by the SfM-based materials (Clapuyt et al., 2015). We believe that our approach, carried out without use of GCPs, is also accurate because the accuracy is kept within every single orthophotomap as discussed above. We do not use the digital elevation model (DEM) of differences (DoD) and hence the highly accurate Earth-fixed reference is not needed. We believe that the presence of a potential shift between two spatial data sets does not cause meaningful changes in area of the considered objects. To support this assumption we refer to a recent paper by Mesas-Carrascosa et al. (2014), who focus on UAV-based area calculation and argue that "Other shortcomings include the lack of vertical adjustment of the aerial camera and the unknown or variable interior orientation of the camera. These factors affect point position accuracy but do not necessarily decrease the accuracy of area measurements".

Water extent during high flow, or inundation if overbank flow occurs, is identified on orthophotomaps as maximum range of terrain covered by water. Calculations of water surface areas were carried out to compare water extents recorded on different dates. Thus, having a series of five orthophotomaps for each site (S1, S2, .., S9), corresponding to the 

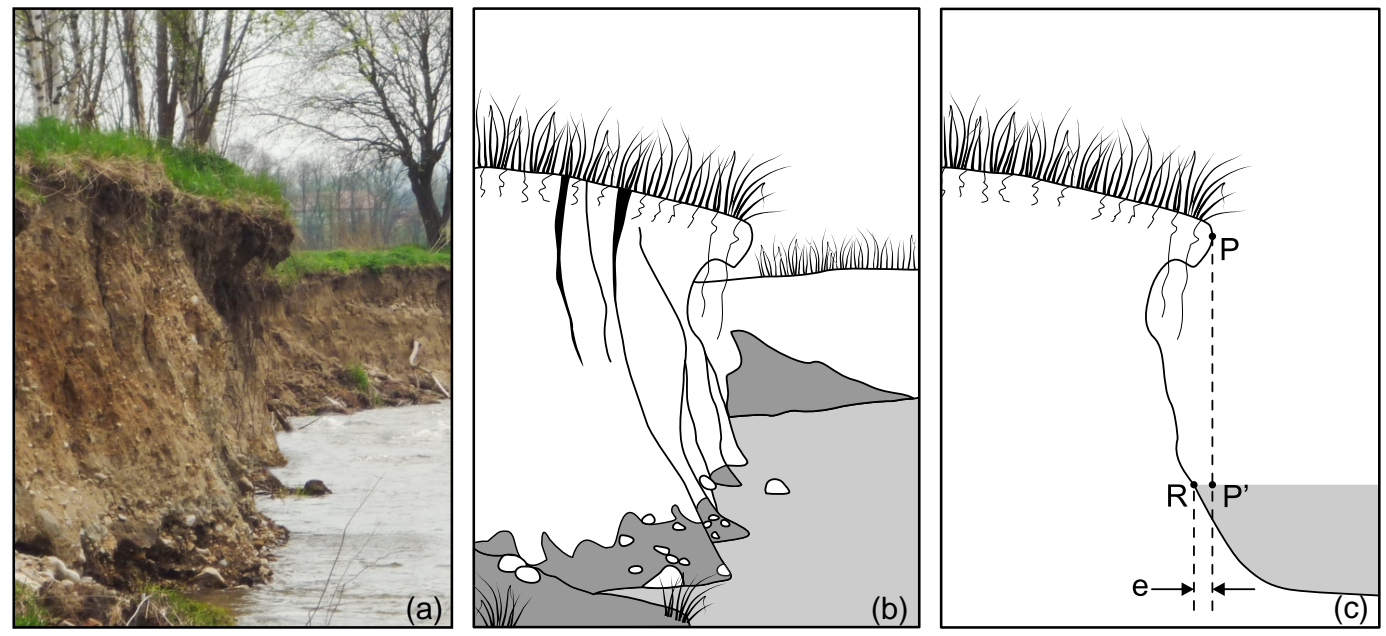

Figure 4. Undercut river bank: (a) photograph, (b) three-dimensional (3-D) sketch, (c) 2-D cross section with edge $\mathrm{P}$ and its projection onto water surface $P^{\prime}$ (water surface visible from the UAV) as well as true bank $R$ (UAV-unobservable water surface, denoted in the figure as " $e$ ", stretches between $R$ and $\left.P^{\prime}\right)$.

above-mentioned dates of observations, we produced polygons in order to calculate the areas of water extent. To accurately carry out such a polygon generation procedure, the following method-related problems should be addressed: (1) the procedure to determine the edges of water extent should be well-documented to enable its repetition, (2) the accuracy of digitization may vary across cartographic scales and experts, and therefore the impact of these factors should be controlled and (3) there should be a recommended procedure for computing water surface area.

One of the most important factors that may potentially constrain the polygon generation accuracy is related to vegetation. Mapping vegetation with UAVs becomes popular as a recent paper by Husson et al. (2014) confirms. These authors focus on delineating edges between water and nonsubmerged aquatic as well as riparian species, using geographic information system (GIS) tools applied to process images taken by unmanned aerial system (UAS). They delineated the edges by hand on paper printouts and argued that "vegetation mapping, i.e. digitizing the UAS orthoimages, was performed manually by a human interpreter in a GIS using ArcGIS software". Although we concentrate on a fluvial environment, we followed the concept of Husson et al. (2014) of the manual expert-based digitization. Our digitization was practically carried out by two experts (GIS specialist and fluvial geomorphologist). Therefore, we believe that the accuracy of the produced water surface areas is acceptable and are aware of limitations, the reasons of which are graphically presented in Figs. 4 and 5.

Not only vegetation but also morphology was found to be important when determining the boundaries of water extent. The extent in question is relatively easy to identify if the water reaches a clear barrier, such as for instance undercut river banks, defence river banks, levees or dams. The water extent within plains as well as for rivers of indistinct and small slope banks, which additionally may be accompanied by bars, is difficult to determine. A similar problem refers to banks of mid-channel forms.

Soil-turf overhangs on undercut river banks as well as clumps of grass growing on the low banks make the line along which water meets the land invisible (Fig. 4). Hence, the extent is determined as a line connecting the gaps between the clumps of grass (Fig. 5a and b). Bushes as well as small trees growing on the edge of a river channel also make a riverbank invisible. In such cases, water extent is drawn as a line interpolated between the last exposed parts of a riverbank at both ends of woodlots or bushes (Fig. $5 \mathrm{c}$ and d). This procedure is verified against the field observations as well as against orthophotomaps for November 2012, January 2013 and December 2013 (absence of leaves). Sections of river channel, for which it was impossible to determine the water extent in accordance with the procedure described above, were withdrawn from the analysis. The procedure enables the determination of water extent with certain approximation. Following the above discussion on the temporal analysis of landform topography without GCPs, it is assumed that determination errors are similar for all nine sites and five dates. This allows us to compare areas computed for different dates.

Digitization of water extent was conducted using ArcMap 10.2.2. To accurately measure the area, the spatial data were transformed into the cylindrical equal area projection in secant normal aspect, with longitude of the central meridian at $13.5^{\circ} \mathrm{W}$ and standard parallels at $51^{\circ} \mathrm{S}$ and $51^{\circ} \mathrm{N}$. The accuracy of digitization (minimum dimension of digitized features, e.g. channels between clumps or width of islands) was $10 \mathrm{~cm}$, while the resolution of orthophotomaps was approximately equal to $3 \mathrm{~cm}$. 

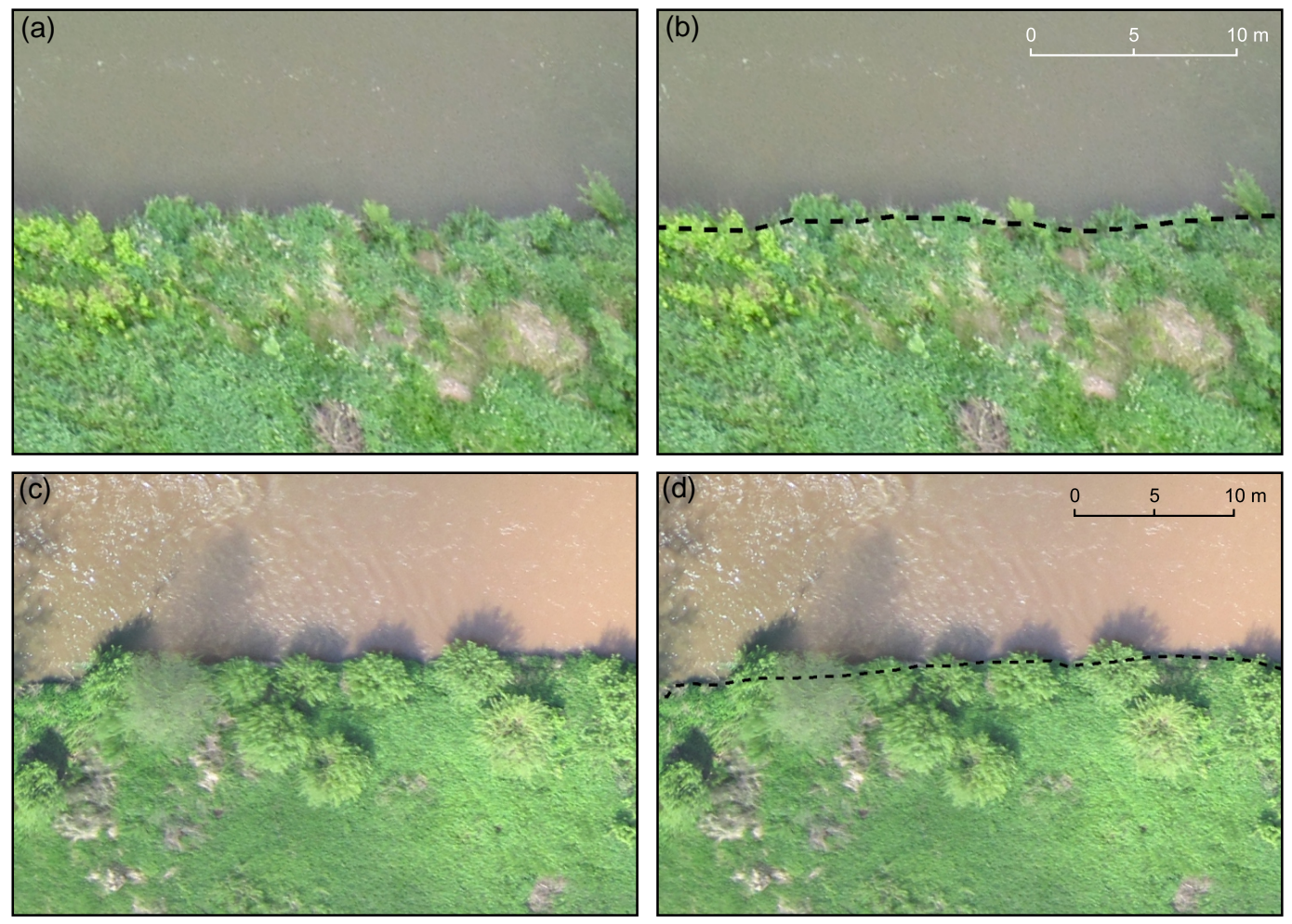

Figure 5. Determination of water surface areas: $(\mathbf{a}, \mathbf{b})$ as a line connecting the gaps between the clumps of grass on undercut river bank covered by soil-turf overhangs, $(\mathbf{c}, \mathbf{d})$ as a line interpolated between last exposed parts of riverbank at both ends of woodlots or bushes.

\subsection{Riverflow data}

As a hydrologic reference for the low-, normal- and highflow situations, we use the water level data recorded at the adjacent gauge in Gorzuchów (south of S8 in Fig. 3), which belongs to a larger Local System for Flood Monitoring, named LSOP (Lokalny System Ostony Przeciwpowodziowej). The observations at the gauge are carried out in the real-time fashion every $15 \mathrm{~min}$.

Figure 6 presents the hydrographs observed over one complete week when UAV flights were performed, with superimposed dots that highlight the water level at the time of the UAV observation. In all cases the warning and emergency (alarm) water levels were depicted for reference.

In order to classify water into low-, normal-, and highflow stages, we analysed the daily data from the same gauge that, since the beginning of the records in 1981 by the Institute of Meteorology and Water Management - National Research Institute (IMGW-PIB), has been used to measure levels. For the hydrologic years 1982-2014 (note that in Poland a hydrologic year begins on 1 November), hence for the period 1 November 1981-31 October 2014, we computed (in parentheses abbreviations used in the Polish hydrologic nomenclature are given) (1) minimum from a time series of annual minimum water levels (NNW), (2) maximum from a time series of annual minimum water levels
(WNW), (3) minimum from a time series of annual mean water levels (NSW), (4) maximum from a time series of annual mean water levels (WSW), (5) minimum from a time series of annual maximum water levels (NWW), (6) maximum from a time series of annual maximum water levels (WWW). Figure 7 presents three graphs (annual min, annual mean, annual max) from which we extracted the abovementioned characteristics. Three classes of water levels exist - i.e. low, mean and high stages - in additional to a distinct intermediate class between mean and high stages (Fig. 7). In contrast, there is no intermediate class between low and mean stages since NSW is smaller than WNW. It is apparent form Figs. 6, 7 and Table 2 that we consider two lowstage situations (27 November 2012, 21 August 2013), one mean-stage situation (27 September 2013), one intermediatestage situation (2 June 2014) and one high-stage situation (13 May 2013).

\section{Methods}

\subsection{Concept}

Let us assume that we have $m$ UAV-based orthophotomaps that consist of observations of the same part of river channel carried out at times $t_{1}, \ldots, t_{n}$. Let us consider only such fragments of the orthophotomaps, which meet the criteria 

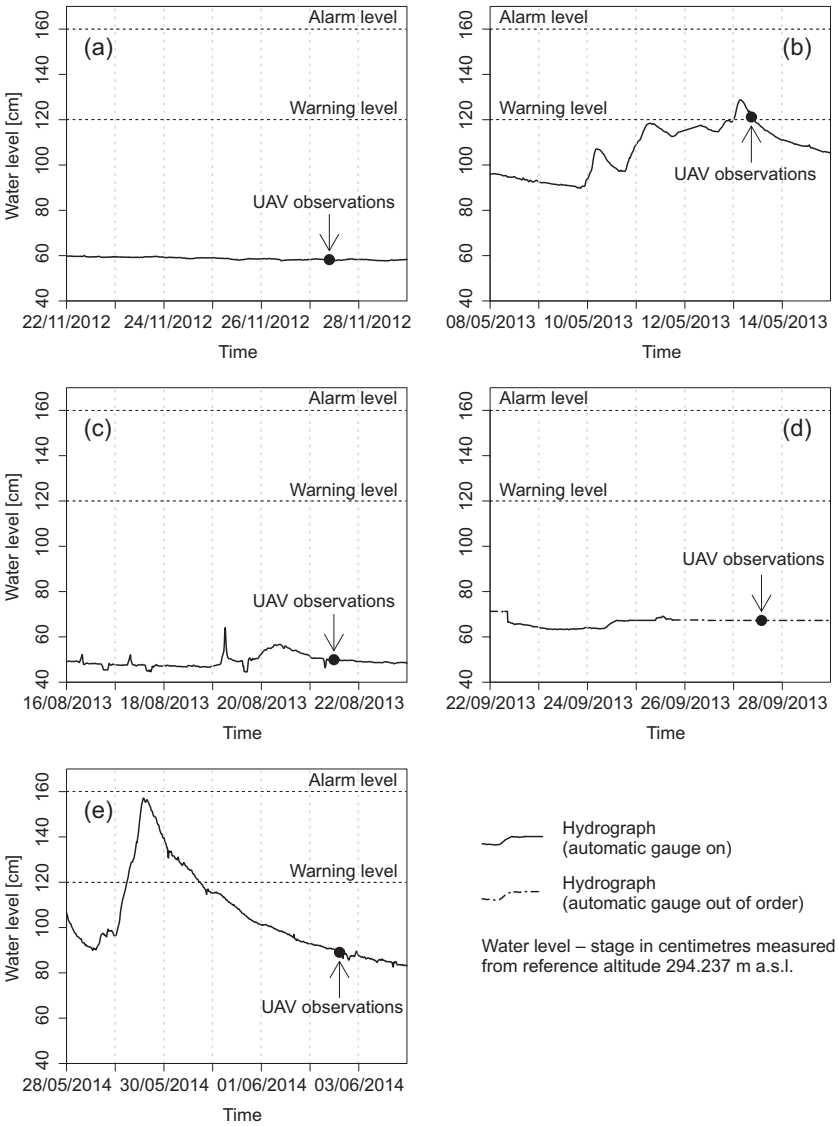

Water level - stage in centimetres measured from reference altitude $294.237 \mathrm{~m}$ a.s.l.

Figure 6. Hydrographs recorded in Gorzuchów before (approx. 5 days) and after (approx. 2 days) UAV flights on (a) 27 November 2012, (b) 13 May 2013, (c) 21 August 2013, (d) 27 September 2013 and (e) 2 June 2014.

Table 2. Water levels in Gorzuchów during the UAV flights on 27 November 2012, 13 May 2013, 21 August 2013, 27 September 2013 and 2 June 2014 along with description of hydrograph features and stage classification.

\begin{tabular}{lcll}
\hline Date & $\begin{array}{c}\text { Water level } \\
\text { in centimetres } \\
\text { at UAV flight }\end{array}$ & $\begin{array}{l}\text { Phase or shape of } \\
\text { hydrograph at or } \\
\text { around UAV flight }\end{array}$ & $\begin{array}{l}\text { Stage classification } \\
\text { based on Fig. 7 }\end{array}$ \\
\hline $27 / 11 / 2012$ & 58 & flat & low stage \\
$13 / 05 / 2013$ & 121 & peak flow & high stage \\
$21 / 08 / 2013$ & 50 & flat & low stage \\
$27 / 09 / 2013$ & 67 & flat (uncertain) & $\begin{array}{l}\text { mean stage } \\
2 / 06 / 2014\end{array}$ \\
& 89 & recession limb & intermediate stage \\
\hline
\end{tabular}

outlined in Sect. 2.1. Therefore, for each orthophotomap we obtain $n$ sites, coded as $\mathrm{S} 1, \ldots, \mathrm{Sn}$, in which water extent should be estimated. Such water-covered areas are expressed by polygons (coded according to sites as $s_{1}, \ldots, s_{n}$ ), the production of which should follow the procedure outlined in Sect. 2.2. Having produced the polygons, we are able to cal-

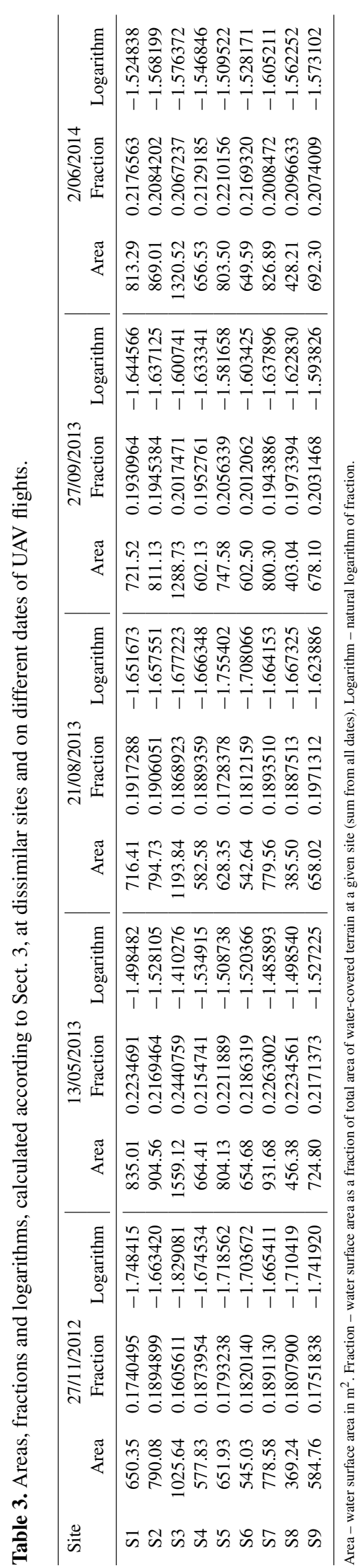

Hydrol. Earth Syst. Sci., 20, 3193-3205, 2016 


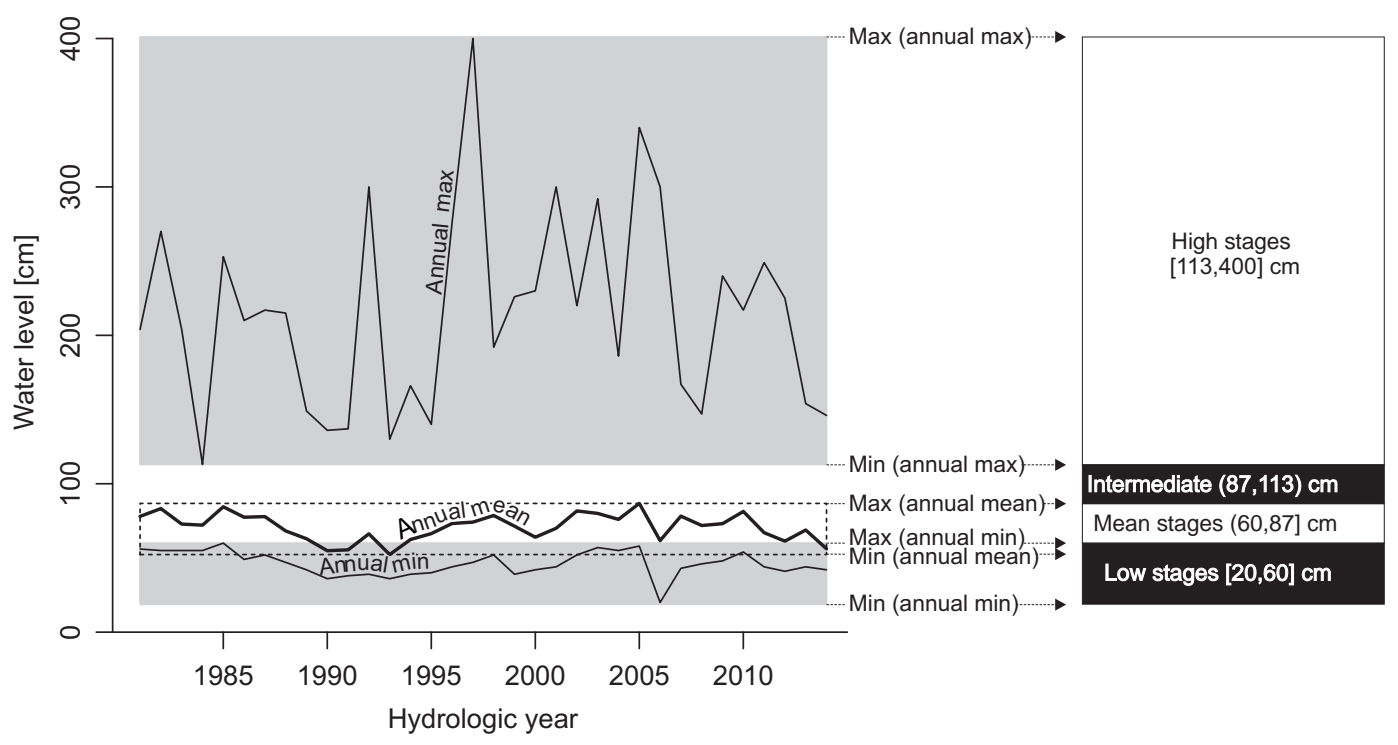

Zones of annual maximum or annual minimum river stages

Zone of annual mean river stages

Figure 7. Time series of annual minimum, annual mean, annual maximum river stage computed for Gorzuchów in hydrologic years 19822014 (note that in Poland a hydrologic year begins on 1 November) along with their main statistics and the resulting characteristic river stage classes.

culate water surface areas. Hence, we consider a matrix A:

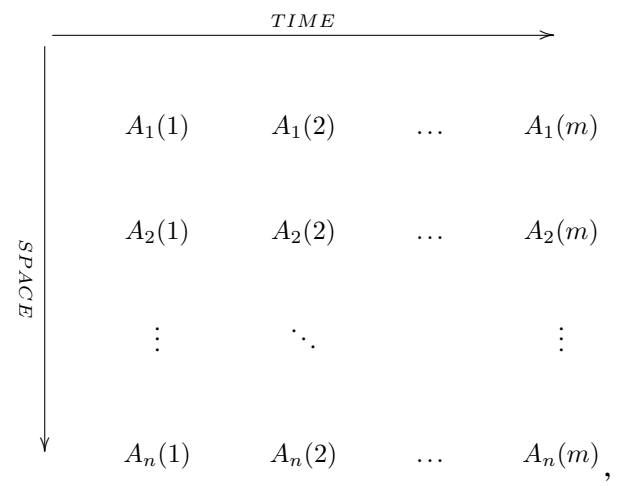

where $A_{s}(t)$ is water surface area at site $s$ at time $t$. In order to obtain the version of these data, which is independent of sizes of $\mathrm{S} 1, \ldots \mathrm{Sn}$ (and the corresponding polygons $s_{1}, \ldots, s_{n}$ ), we transform the areas by computing the ratio of water surface area at a given section $s_{i}(i=1, \ldots, n)$ and at a given time $t_{j}$ $(j=1, \ldots, m)$ to a sum of water surface areas in $m$ episodes that occurred at times $t_{1}, \ldots, t_{m}$ at the same site $s_{i}$. This ratio matrix, denoted by $\mathbf{R}$, is composed of the following elements:

$R_{i}(j)=\frac{A_{i}(j)}{\sum_{k=1}^{m} A_{i}(k)}$.

The transformation allows us to consider $m$ samples $\mathbf{R}(1)=$ $\left[R_{1}(1), \ldots, R_{n}(1)\right], \ldots, \mathbf{R}(m)=\left[R_{1}(m), \ldots, R_{n}(m)\right]$; however, they should follow the i.i.d. (independent and identically distributed) property to be analysed as statistical samples. The popular transformation that helps to attain this goal is based on a logarithmic function, which in our case produces a new matrix $\mathbf{L}$, the elements of which are computed as $L_{i}(j)=\ln \left[R_{i}(j)\right]$. The corresponding samples are denoted as $\mathbf{L}(1)=\left[L_{1}(1), \ldots, L_{n}(1)\right], \ldots, \mathbf{L}(m)=$ $\left[L_{1}(m), \ldots, L_{n}(m)\right]$.

Let us now formulate a research hypothesis to be verified. Consider two samples $\mathbf{L}(j)$ and $\mathbf{L}(k), j \neq k$. We aim to check whether water surface areas at the time $k$ are significantly greater than at the time $j$. The hypothesis may be expressed in terms of means, i.e.

- H0: two samples have the same mean water surface areas.

- H1: the mean water surface area is greater in the subsequent, $\mathbf{L}(k)$, sample than in the preceding one, $\mathbf{L}(j)$.

Such a problem of pairwise comparison of samples may be solved using the Student's $t$ test; however, numerous assumptions must be fulfilled prior to its application. Indeed, each of the samples $\mathbf{L}(j)$ and $\mathbf{L}(k)$ should be i.i.d., follow the normal distribution and the two data sets should have the same variances. Several standard statistical tests can be used to check these assumptions:

- independence, Ljung-Box test (Ljung and Box, 1978);

- normality, Shapiro-Wilk test (Shapiro and Wilk, 1965; Royston, 1995);

- symmetry, D'Agostino test (D'Agostino, 1970);

- mesokurticity, Anscombe-Glynn test (Anscombe and Glynn, 1983); 
- equality of variances, $F$ test (Box, 1953).

If the assumptions are fulfilled, the Student's $t$ test can be applied to test $\mathrm{H} 0$ against $\mathrm{H} 1$. However, if the sample size is small, the bootstrapped Student's $t$ test should be applied to verify the asymptotic results. Following the idea of Efron (1979), $B$ values of the Student's statistics should be computed, and their mean leads to the bootstrapped solution. If the bootstrapped solution confirms the asymptotic one, the decision on the hypothesis can be made.

\subsection{Interpretation through numerical exercise}

The two sample Student's $t$ test is used to test a null hypothesis (H0) that means of two samples are equal, but three alternative hypotheses are allowed. These three alternatives include the following: means of two samples are different, mean of the first sample is bigger than mean of the second sample and mean of the second sample is bigger than mean of the first sample. In the latter two alternatives, the order of samples is important and has an impact on where the rejection region is located. Knowing the aforementioned basics, we stated the research hypothesis $\mathrm{H} 0$ with its alternative $\mathrm{H} 1$ on purpose, in the way that rejection of the null hypothesis implies acceptance of the alternative one (and this unequivocally indicates that the second area is meaningfully bigger).

In order to clarify the formulation of the hypotheses $\mathrm{H} 0$ and $\mathrm{H} 1$ the following numerical exercise is proposed. Let us consider two combinations of $\mathbf{L}(j)$ and $\mathbf{L}(k)$. Recall that we test if means of $\mathbf{L}(j)$ and $\mathbf{L}(k)$ are equal, with the alternative that the mean of $\mathbf{L}(j)$ is smaller than the mean of $\mathbf{L}(k)$. Let us consider two cases based on data borrowed from Table 2 .

\subsubsection{Case 1}

Let us assume that

$j=27$ November 2012,

$k=13$ May 2013,

mean of $\mathbf{L}(27$ November 2012) $=-1.71727$,

mean of $\mathbf{L}(13$ May 2013) $=-1.501393$.

Arithmetically, mean of $\mathbf{L}(27$ November 2012) is smaller than mean of L(13 May 2013). This inequality has also been confirmed statistically (the bootstrapped Student's $t$ test) at the significant level of 0.01 (later it is shown that the difference in means is statistically significant). Hence, in this case a subsequent episode (time step $k$ ) revealed meaningfully bigger water surface area than the preceding one (time step $j$ ).

\subsubsection{Case 2}

Let us unrealistically assume a reverse order of the abovementioned numbers, namely

$j=13$ May 2013,

$k=27$ November 2012 .
Arithmetically, mean of L(13 May 2013) is not smaller than mean of $\mathbf{L}(27$ November 2012). If we test the null hypothesis (mean of $\mathbf{L}(j)$ is equal to mean of $\mathbf{L}(k)$ ) against the alternative hypothesis (mean of $\mathbf{L}(j)$ is smaller than mean of $\mathbf{L}(k)$ ), we cannot reject the null hypothesis with the bootstrapped Student's $t$ test at the significance level of 0.01 . Hence, in this case a subsequent episode (time step $k$ ) does not reveal a meaningfully bigger water surface area than the preceding one (time step $j$ ).

\section{Results and discussion}

It is apparent from Fig. 8 that fragments of sites $\mathrm{S} 1-\mathrm{S} 9$ are covered with water, the extent of which is dissimilar at different dates of UAV observations. These dates correspond to low-, normal-, intermediate- and high-flow situations (see Sect. 2.3). Water surface areas in sites S1-S9 are juxtaposed in Table 3. Along the lines of Eq. (1), Table 3 presents the ratios $R_{i}(j)$ and their logarithms $L_{i}(j)-$ for $i=1, \ldots, 9$ and $j=1, \ldots, 5$. The latter numbers become input data for the subsequent analysis.

Since we aim to compare five samples $\mathbf{L}(1), \ldots, \mathbf{L}(5)$, we first have to verify if they follow the i.i.d. structure. The $p$ values of the Ljung-Box, Shapiro-Wilk, D'Agostino and Anscombe-Glynn tests - juxtaposed in Table 4 - indicate that the five data sets are trajectories of statistical samples (sequences of i.i.d. random variables) from the normal distribution. This can be inferred at the significance level of 0.013 or smaller. It is worth commenting here on statistical independence, which should be understood in our exercise as an "internal" independence within each sample. Every sample is produced from areas of polygons spatially distributed along the river. In particular, the Ljung-Box test provides arguments for such an independence since $p$ values are equal to $0.059,0.092,0.444,0.713$ and 0.828 , for five consecutive dates. Hence, from a definition of statistical independence we infer that they cannot reveal autocorrelation. In addition, variances between each pair of $\mathbf{L}(1), \ldots, \mathbf{L}(5)$ are shown to be similar at the significance level of 0.03 or smaller, as the Fisher's test suggests (Table 5). The statistical inference shows that the assumptions of the Student's $t$ tests are fulfilled.

Subsequently, we apply the Student's $t$ test to verify the above-mentioned hypothesis H0 against H1 (see Sect. 3), and we do so for each pair from $\mathbf{L}(1), \ldots, \mathbf{L}(5)$. The results are presented in Table 6, which juxtaposes $p$ values of the test, computed as asymptotic and bootstrapped solutions. The values in bold indicate statistically significant differences in water surface areas, which suggests the rejection of the H0 hypothesis. This means that the mean water surface area is shown to be greater in the subsequent $\mathbf{L}(k)$ sample than in the preceding one.

It is known that water surface area is correlated with river stage. The characteristics of such relationships are reviewed 
Table 4. $P$ values of a few statistical tests applied to input data for the UAV flights on 27 November 2012, 13 May 2013, 21 August 2013, 27 September 2013 and 2 June 2014.

\begin{tabular}{lccccc}
\hline \multirow{2}{*}{ Test } & \multicolumn{4}{c}{$P$ value for a given observation } \\
\cline { 2 - 6 } & $27 / 11 / 2012$ & $13 / 05 / 2013$ & $21 / 08 / 2013$ & $27 / 09 / 2013$ & $2 / 06 / 2014$ \\
\hline Independence (Ljung-Box) & 0.059 & 0.092 & 0.444 & 0.713 & 0.828 \\
Normality (Shapiro-Wilk) & 0.208 & 0.013 & 0.178 & 0.321 & 0.863 \\
Symmetry (D'Agostino) & 0.265 & 0.076 & 0.247 & 0.758 & 0.979 \\
Mesokurticity (Anscombe-Glynn) & 0.193 & 0.017 & 0.132 & 0.171 & 0.759 \\
\hline
\end{tabular}

Table 5. $P$ values of the Fisher's test applied to check if variances of input data are the same in each pair of the UAV observations.

\begin{tabular}{lccccc}
\hline Date & \multicolumn{5}{c}{$P$ value of Fisher's test between two observations } \\
\cline { 2 - 6 } & $27 / 11 / 2012$ & $13 / 05 / 2013$ & $21 / 08 / 2013$ & $27 / 09 / 2013$ & $2 / 06 / 2014$ \\
\hline $27 / 11 / 2012$ & 1.000 & 0.385 & 0.373 & 0.030 & 0.144 \\
$13 / 05 / 2013$ & 0.385 & 1.000 & 0.980 & 0.170 & 0.536 \\
$21 / 05 / 2013$ & 0.373 & 0.980 & 1.000 & 0.178 & 0.552 \\
$27 / 09 / 2013$ & 0.030 & 0.170 & 0.178 & 1.000 & 0.440 \\
$2 / 06 / 2014$ & 0.144 & 0.536 & 0.552 & 0.440 & 1.000 \\
\hline
\end{tabular}

by Smith (1997). Usually, the correlations are positive, quasilinear for rivers (Usachev, 1983) and even strongly linear for lakes (Xia et al., 1983). Hence, when water surface areas are analysed in this paper in combination with river stages and their classes (Fig. 7) the following transitions are found to be meaningfully observable.

- Low stages (27 November 2012 and 21 August 2013) $\rightarrow$

- mean stage (27 September 2013)

- intermediate stage (2 June 2014)

- high stage (13 May 2013).

- Mean stage (27 September 2013) $\rightarrow$

- intermediate stage (2 June 2014)

- high stage (13 May 2013).

- Intermediate stage (2 June 2014) $\rightarrow$

- high stage (13 May 2013).

Noteworthy is the fact that the other transitions are found to be insignificant. To verify the adequacy of the detected changes between the water surface areas, we again refer to Fig. 6 and Table 2, which present stages observed at the Gorzuchów gauge at the time of the UAV observations. The visual examination of the graphs and table indicates that no changes in water-covered areas correspond to no changes in river stages and, conversely, significant differences in water surface areas observed by the UAV at dissimilar times correspond to visually well seen changes of water levels. This inference allows us to positively verify the research hypothesis stated in this paper. Namely, even small changes in water surface areas are observable using the UAV and - in addition - meaningful changes of river stages can also be inferred from the orthophotomaps based on the UAV-taken visible light photographs.

A remark should be given here about the nonchronological order of the above-mentioned transitions. These numbers serve as examples of low, mean, intermediate and high water levels. They have been recorded by a real UAV on different dates. We used the UAV-observed water surface areas as true data that represent the aforementioned stages. We believe that, for the analysis that aims to check the procedure proposed in this paper, the chronological order of transitions between stages is not important. It would be ideal to have the chronological set of transitions; however, such a data set is not available for our experiment. Thus, we mixed the order to check various potential combinations of transitions in order to test the procedure on the real UAV-acquired data.

A note should be given on the accuracy of the elaborated approach. We believe that potential sources of error may reside in (1) the SfM accuracy, (2) application of the SfM without GCPs, (3) problems with the determination of water boundaries due to presence of vegetation and undercuts. The quality of outputs from the SfM procedure depends on many factors - e.g. texture and light, which influence a number of keypoints in every image - and hence not uncommonly we produce incomplete orthophotomaps from well-overlapped photographs. Despite these constraints the SfM procedure is well-established in scientific applications and is probably the most commonly used and accepted method for producing dense point clouds from the photographs taken by the consumer-grade cameras (Westoby et al., 2012). As stated 


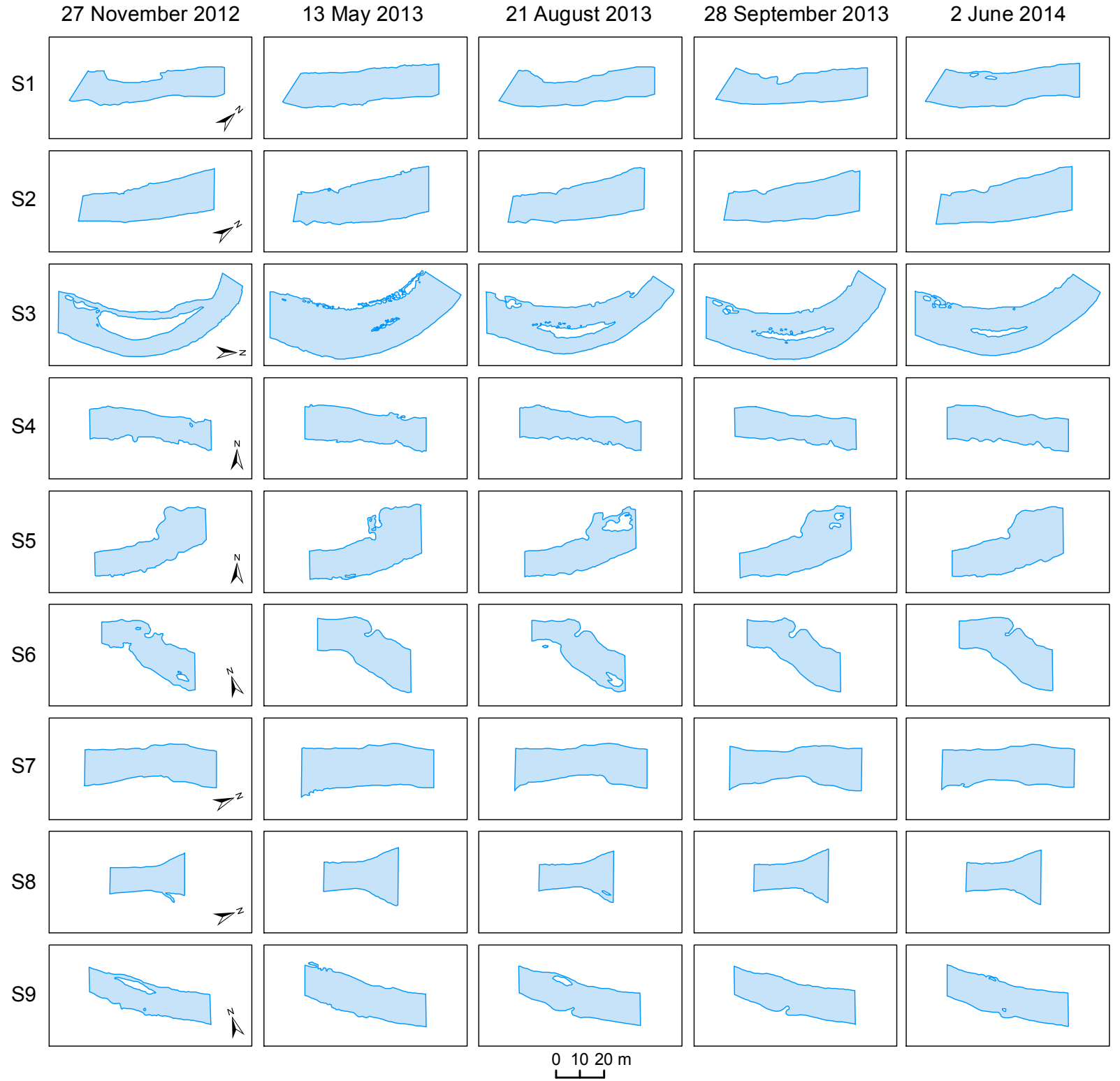

Figure 8. The water extents in the analysed sections in the Ścinawka channel in Gorzuchów on 27 November 2012, 13 May 2013, 21 August 2013, 27 September 2013 and 2 June 2014. Numbers of the sites (on the left) are the same as in Fig. 3.

Table 6. $P$ values of asymptotic and bootstraped the Student's $t$ test applied to identify significant differences between water surface areas observed on 27 November 2012, 13 May 2013, 21 August 2013, 27 September 2013 and 2 June 2014. Bold values indicate statistically significant transitions.

\begin{tabular}{|c|c|c|c|c|c|c|c|c|c|c|}
\hline & \multicolumn{2}{|c|}{$27 / 11 / 2012$} & \multicolumn{2}{|c|}{$13 / 05 / 2013$} & \multicolumn{2}{|c|}{$21 / 08 / 2013$} & \multicolumn{2}{|c|}{$27 / 09 / 2013$} & \multicolumn{2}{|c|}{$2 / 06 / 2014$} \\
\hline & Asymptotic & Bootstrapped & Asymptotic & Bootstrapped & Asymptotic & Bootstrapped & Asymptotic & Bootstrapped & Asymptotic & Bootstrapped \\
\hline $27 / 11 / 2012$ & 0.5000000 & 0.5000000 & 0.0000000 & 0.0000000 & 0.0318682 & 0.0240133 & 0.0000377 & 0.0000100 & 0.0000002 & 0.0000000 \\
\hline $13 / 05 / 2013$ & 1.0000000 & 1.0000000 & 0.5000000 & 0.5000000 & 1.0000000 & 1.0000000 & 0.9999997 & 1.0000000 & 0.9978170 & 0.9987431 \\
\hline $21 / 08 / 2013$ & 0.9681318 & 0.9769138 & 0.0000000 & 0.0000000 & 0.5000000 & 0.5000000 & 0.0006099 & 0.0002194 & 0.0000007 & 0.0000001 \\
\hline $27 / 09 / 2013$ & 0.9999623 & 0.9999903 & 0.0000003 & 0.0000000 & 0.9993901 & 0.9997737 & 0.5000000 & 0.5000000 & 0.0000703 & 0.0000258 \\
\hline $2 / 06 / 2014$ & 0.9999998 & 1.0000000 & 0.0021830 & 0.0012121 & 0.9999993 & 0.9999999 & 0.9999270 & 0.9999738 & 0.5000000 & 0.5000000 \\
\hline
\end{tabular}


in Sect. 2.2, we do not use GCPs and believe that this does not undermine our approach. Indeed, we infer from multitemporal UAV-acquired data, in a similar way to the analyses by Clapuyt et al. (2015) and Miřijovský and Langhammer (2015), and calculate water surface areas which are accurate due to internal accuracy of every single orthophotomap (shifts of dissimilar orthophotomaps due to lack of GCPs are negligible).

As mentioned in Sect. 2.2, we refer to the reasoning of Mesas-Carrascosa et al. (2014), who claim that the computation of area is not vulnerable to changes in point position accuracy. Such changes may be due to neglecting GCPs. We perform manual georeferencing, which was also carried out in a different way by Peter et al. (2014), who omitted measuring GCPs in the field and identified them manually on external spatial data sources.

Finally, a comment should be given on how vegetation and undercuts constrain the determination of water boundaries. In Sect. 2.2 we proposed a procedure to cope with the problem, but we are aware of its subjectivity. However, even satellitebased observations, using different sensors including radar, reveal similar limitations (Smith, 1997).

It is also important to discuss limitations, which may constrain extrapolation of the results to other rivers. Channel morphology, mainly the slope of banks, may have a significant impact on the observation of water surface area with the UAV. Therefore, the results prepared for a specific river in the SW Poland are not transferable to other rivers with different cross-sectional parameters. Indeed, Smith (1997) argues that "Until additional empirical rating curves relating inundation area to ground measurements of stage or discharge are made, it is difficult to assess their potential for extrapolation to other rivers of similar morphology. However, it seems likely that such curves will vary significantly between rivers and therefore must be constructed for each site". However, our approach focuses mainly on a statistical analysis of water surface areas, not river stages themselves. In fact, we quantitatively infer on statistically meaningful changes in water surface area (this is a key part of our procedure) and only qualitatively, through the existence of a relationship between water surface areas and river stages published by Usachev (1983), extrapolate our results into changes in river stages. We believe that our quantitative approach (recall that this concerns seeking changes in water surface areas in the orthophotomaps produced from the UAV-taken photographs) forms a general method that - under several conditions clearly identified in the manuscript - may be applied in other regions. However, the use of the approach to infer on river stages should be made with caution, since such an extrapolation requires a knowledge about the relationship between water surface areas and river stages (and the characteristics of this relation are vulnerable to sites-specific river morphology, especially bank slopes).

\section{Conclusions}

We have shown that it is possible to detect even small changes in water surface area, using multitemporal orthophotomaps based on the UAV-acquired images. This can be done by the UAV equipped with the RGB consumer-grade camera, which takes photographs with a sufficient overlap to produce the SfM-based dense point cloud and, consequently, an orthophotomap.

It is likely that transitions from normal or low flow to high flow does not produce large water surface area, as exemplified in Fig. 1. Our approach, verified in the experiment that uses the UAV data acquired at nine study sites during the campaign consisted of five observations, shows that it is possible to detect transitions between water surface areas produced by all characteristic water levels (low, mean, intermediate and high stages), and such a detection is statistically significant. Since water surface areas are correlated with river stages our approach can also be used as a tool for observing characteristic river stages.

More specifically, we detected any rise of water level from low stages to mean, intermediate and high stages. We also found any increase in water level from mean stages to intermediate and high stages. Moreover, we detected rise of water level from intermediate stages to high stages. The detection was based on a rigorous statistical inference, based on several statistical tests performed in the asymptotic and bootstrap fashion.

Finally, it is important to identify potential applications of our approach. To do this we recall our motivation, stated in Sect. 1. We developed a solution, known as the HFU, which integrates the real-time flood warning system (HydroProg) with the hydrodynamic model (FloodMap) and their nearreal-time verification using UAVs (Niedzielski et al., 2015). A key problem in the HFU approach is the uncertainty of estimating water surface areas. The results presented in this paper unequivocally show that the UAV observes water extent with acceptable accuracy and, in addition, river stages can be inferred from the observations. The later feature opens new perspectives for applications of the approach in the process of monitoring water levels of rivers in ungauged basins.

Acknowledgements. The research has been financed by the National Science Centre, Poland, through the grant no. 2011/01/D/ST10/04171 under leadership of Tomasz Niedzielski. The UAV has been purchased from the statutory funds of the Institute of Geography and Regional Development of the University of Wrocław, Poland. The authors kindly acknowledge the authorities of the County Office in Kłodzko for productive partnership and making the data of the Local Flood Monitoring System (Lokalny System Osłony Przeciwpowodziowej - LSOP) available for scientific purposes. We also acknowledge the Institute of Meteorology and Water Management - National Research Institute (IMGW-PIB) for providing us with access to hydrological data. We are grateful to Jacek Ślopek and Justyna Jeziorska, for 
their support in the selected field experiments.

Edited by: H. Mitasova

Reviewed by: two anonymous referees

\section{References}

Anscombe, F. J. and Glynn, W. J.: Distribution of kurtosis statistic for normal statistics, Biometrika, 70, 227-234, 1983.

Box, G. E. P.: Non-Normality and Tests on Variances, Biometrika, 40, 318-335, 1953.

Cobby, D. M., Mason, D. C., and Davenport, I. J.: Image processing of airborne scanning laser altimetry data for improved river flood modelling, ISPRS J. Photogramm., 56, 121-138, 2001.

Clapuyt, F., Vanacker, V., and Van Oost, K.: Reproducibility of UAV-based earth topography reconstructions based on Structure-from-Motion algorithms, Geomorphology, 260, 4-15, doi:10.1016/j.geomorph.2015.05.011, 2015.

D'Agostino, R. B.: Transformation to Normality of the Null Distribution of G1, Biometrika, 57, 679-681, 1970.

Dubicki, A., Malinowska-Małek, J., and Strońska, K.: Flood hazards in the upper and middle Odra River basin - A short review over the last century, Limnologica, 35, 123-131, 2005.

Efron, B.: Bootstrap Methods: Another Look at the Jackknife, Ann. Stat., 7, 1-26, 1979.

Husson, E., Hagner, O., and Ecke, F.: Unmanned aircraft systems help to map aquatic vegetation, Appl. Veg. Sci., 17, 567-577, 2014.

Kasprzak, M.: Wezbrania i powodzie na rzekach Dolnego Śląska, in: Wyjątkowe zdarzenia przyrodnicze na Dolnym Śląsku i ich skutki, edited by: Migoń, P., Rozprawy Naukowe Instytutu Geografii i Rozwoju Regionalnego Uniwersytetu Wrocławskiego, 14, 81-140, 2010.

Kouraev, A. V., Zakharova, E. A., Samain, O., Mognard, N. M., and Cazenave, A.: Ob' river discharge from TOPEX/Poseidon satellite altimetry (1992-2002), Remote Sens. Environ., 93, 238245, 2004.

Lang, M. W. and McCarty, G. W.: Lidar intensity for improved detection of inundation below the forest canopy, Wetlands, 29, 1166-1178, 2009.

Latocha, A. and Parzóch, K.: Efekty geomorfologiczne powodzi w dolinie Białej Lądeckiej w czerwcu 2009 r., Przyroda Sudetów, 13, 251-262, 2010.

Liu, X., Zhang, Z., Peterson, J., and Chandra, S.: LiDAR-Derived High Quality Ground Control Information and DEM for Image Orthorectification, Geoinformatica, 11, 37-53, 2007.

Ljung, G. M. and Box, G. E. P.: On a measure of lack of fit in time series models, Biometrika, 65, 297-303, 1978.

Mesas-Carrascosa, F. J., Notario-García, M. D., Meroño de Larriva, J. E., Sánchez de la Orden, M., and García-Ferrer, A.: Validation of measurements of land plot area using UAV imagery, Int. J. Appl. Earth Obs., 33, 270-279, 2014.

Miřijovský, J. and Langhammer, J.: Multitemporal Monitoring of the Morphodynamics of a Mid-Mountain Stream Using UAS Photogrammetry, Remote Sens., 7, 8586-8609, 2015.

Niedzielski, T., Miziński, B., Kryza, M., Netzel, P., Wieczorek, M., Kasprzak, M., Kosek, W., Migoń, P., Szymanowski, M., Jeziorska, J., and Witek, M.: HydroProg: a system for hydrologic forecasting in real time based on the multimodelling approach, Meteorology Hydrology and Water Management - Research and Operational Applications, 2, 65-72, 2014.

Niedzielski, T., Miziński, B., and Yu, D.: Hydrological forecasting in real time: an experimental integrated approach, in: Geomorphometry for Geosciences, edited by: Jasiewicz, J., Zwoliński, Z., Mitasova, H., and Hengl, T., Bogucki Wydawnictwo Naukowe, Adam Mickiewicz University in Poznań - Institute of Geoecology and Geoinformation, Poznań, 97-101, 2015.

Niedzielski, T. and Miziński, B.: Real-time hydrograph modelling in the upper Nysa Kłodzka river basin (SW Poland): a two-model hydrologic ensemble prediction approach, Stoch. Env. Res. Risk A., doi:10.1007/s00477-016-1251-5, online first, 2016.

Peter, K. D., d'Oleire-Oltmanns, S., Ries, J. B., Marzolff, I., and Hssaine, A. A.: Soil erosion in gully catchments affected by landlevelling measures in the Souss Basin, Morocco, analysed by rainfall simulation and UAV remote sensing data, Catena, 113, 24-40, 2014.

Poser, K. and Dransch, D.: Volunteered geographic information for disaster management with application to rapid flood damage estimation, Geomatica, 64, 89-98, 2010.

Prigent, C., Papa, F., Aires, F., Rossow, W. B., and Matthews, E.: Global inundation dynamics inferred from multiple satellite observations, 1993-2000, J. Geophys. Res.-Atmos., 112, D12107, doi:10.1029/2006JD007847, 2007.

Royston, P.: Remark AS R94: A remark on Algorithm AS 181: The W test for normality, J. Roy. Stat. Soc. C-App., 44, 547-551, 1995.

Schnebele, E., Cervone, G., Kumar, S., and Waters, N.: Real Time Estimation of the Calgary Floods Using Limited Remote Sensing Data, Water, 6, 381-398, 2014.

Shapiro, S. S. and Wilk, M. B.: An analysis of variance test for normality (complete samples), Biometrika, 52, 591-611, 1965.

Smith, L. C.: Satellite remote sensing of river inundation area, stage, and discharge: a review, Hydrol. Process., 11, 1427-1439, 1997.

Usachev, V. F.: Evaluation of food plain inundations by remote sensing methods, in: Proceedings of the Hamburg Symposium, IAHS Publ., 145, 475-482, 1983.

Westoby, M. J., Brasington, J., Glasser, N. F., Hambrey, M. J., and Reynolds, J. M.: "Structure-from-Motion" photogrammetry: A low-cost, effective tool for geoscience applications, Geomorphology, 179, 300-314, 2012.

Witek, M., Jeziorska, J., and Niedzielski, T.: Experimental approach to verify prognoses of floods using the unmanned aerial vehicle, Meteorology Hydrology and Water Management - Research and Operational Applications, 2, 3-11, 2014.

Xia, L., Shulin, Z., and Xianglian, L.: The application of Landsat imagery in the surveying of water resources of Dongting Lake, in: Proceedings of the Hamburg Symposium, IAHS Publ., 145, 483-489, 1983.

Yu, D. and Lane, S. N.: Urban fluvial flood modelling using a twodimensional diffusion wave treatment, part 1: Mesh resolution effects, Hydrol. Process., 20, 1541-1565, 2006a.

$\mathrm{Yu}$, D. and Lane, S. N.: Urban fluvial flood modelling using a two-dimensional diffusion wave treatment, part 2: Development of a sub grid-scale treatment, Hydrol. Process., 20, 1567-1583, $2006 b$. 